\title{
Cloud Computing on Accessing Security of Medical Information on Mobile Phone
}

\author{
ISHIMWE Olivier Angel Kevin ${ }^{1}$ (MscIT) , Musoni Wilson ${ }^{2}(\mathrm{PhD})$, UMUTESI Liliane $^{3}(\mathrm{PhD})$ \\ 1) University of Kigali (UOK) ,Rwanda \\ 2) National Research Tomsk State University (TSU), Russia. \\ 3) University of Kigali (UOK), Rwanda.
}

\begin{abstract}
Mobile Cloud Computing is a network of technology that is up-to-date and helps to store data in a reliable way.in a time when the whole world is obsessed with cloud technology and that is why we want to focus on it, whether in business, medicine and education all cloud technology is needed. In modern times technology is to store our data in cloud technology .in the developed world they are now interested in storing their informations in cloud technology which is why we also thought of using it such as a laptop. A large number of informations are collected, stored, processed and returned to the Electronic Medical Record System (EMR).all patients record need to be stored in a reliable manner so that whenever the patient needs them he or she can easily access them, even if he or she is a doctor when he or she needs access to all the informations that the patient can easily access for example like $x$-ray images where needed, disease reports and more. The availability of patients as long as they visit the hospital thus enhances the quality of care. cloud technology.it is a reliable method that can be used in medicine where the patient's information is stored in a safe place and reduces the storage space on the computer and the patient's information is kept safe and secure.

Keywords - information protection; cloud computing; integrity checks; review cipher documents, electronic medical system
\end{abstract}

\section{INTRODUCTION}

Cloud technology is a new way to reduce and modify existing technologies such as storing information in a database in the event of an accident and you may be missing out on patient or computer information and steal it and find a problem., the other thing is that it will store the patient's information. In fact, everything is normal in any technology used in medicine, especially in the form of data storage. All in all, to make it more accessible to most people in the name of statistics. Cloud is not the last word on the internet, although the internet is the foundation needed for the cloud, the cloud is something more than the internet.

The cloud uses a simple way for anyone where it doesn't need the power on your computer or just buy other expensive hardware, the cloud stores your information in the cloud all you need is to have internet, you feel the cloud technology is limited.
The cloud provides all the information that is provided as an online service and the system and software tools in the database that provide the best and most suitable customer service.

\section{BACKGROUND}

Clouds play an important role in changing the way we work together, especially in medicine. Compared to the traditional way of processing information, the cloud provides many benefits, such as the availability of dedicated tools for assembling, integrating, determining and rediscovering the available resources on demand. . performance of service providers .Calculating the cloud is considered a positive change in the technology that has come together to transform the efficiency of ICT infrastructure. therefore, there is nothing new in any technology used in mathematics where the same technology has been used since time immemorial.

The main goal is to deliver more and better service to many in the name of statistics. Clouds are the best and most efficient way to access the Internet. The cloud is where you go to use technology when you need it, whenever you need it. it does not require storage on your desktop, and when you use the internet you pay for the clouds but when you do not use it you do not pay (Ahmed, 2013). cloud-based information security has reached the top level in aggregation as a strong and likely solution for many solutions. This idea is shared by many different groups, such as university researchers, business decision-makers and government agencies. Many of these similar considerations point to serious security concerns and legal challenges to cloud computing, including the availability of services, the confidentiality of information, the provision of products and the collaboration of celebrities.

\section{PROBLEM OF STATEMENT}

1) The main question for the researchis to see and show how the patient's information wouldbesecureenoughwhenhe or she want edit and the doctor who need edit would getiteasily

2) To show how to store data in the cloud where it does not require the purchase of a computer or laptop to store the data because it will be stored in the cloud

3) Understanding that cloud computing is better than ever, where it requires only internet. 
ISSN No:-2456-2165

\section{METHODS}

Our research was focused on finding a solution to the problem of security of medical informationsystems using mobile phone. Formulating a research topic is very significant in any study. To accessing the security and the advantages and disadvantages of cloud computing using mobile phones, which are cloud-based, and its security impact, the background of the topic was first assessed.For the purpose of this research study, the researchers collected quantitative data as well as qualitative data. Researchers use online interviews and questionnaire used to reach to the objective of this research study. The population chosen to participate in this research were nurses from health institutions, doctors from referrals hospitals in ICT field and other ICT employees who are working in health sector. Due to the goals of this research study, the judgmental sampling used and 87 people were selected. The 68 questionnaires received which indicates the good response rate of 78,160 . The non-probability sampling technique used because researchers only chose the responders based on the skills and knowledge they have to the cloud and e-health and it is for this purpose that the purposive or judgmental sampling technique used (hamed 2016, Uma S, 2003). The judgmental sampling is low-cost and convenient and it is good for time saving and it does not permit generalization and subjective (Uma S, 2003)

\section{Data Analysis and Models}

All patients were prescripted .usingElectronic Medical Record system (EMR).to identify performance and Records into database .
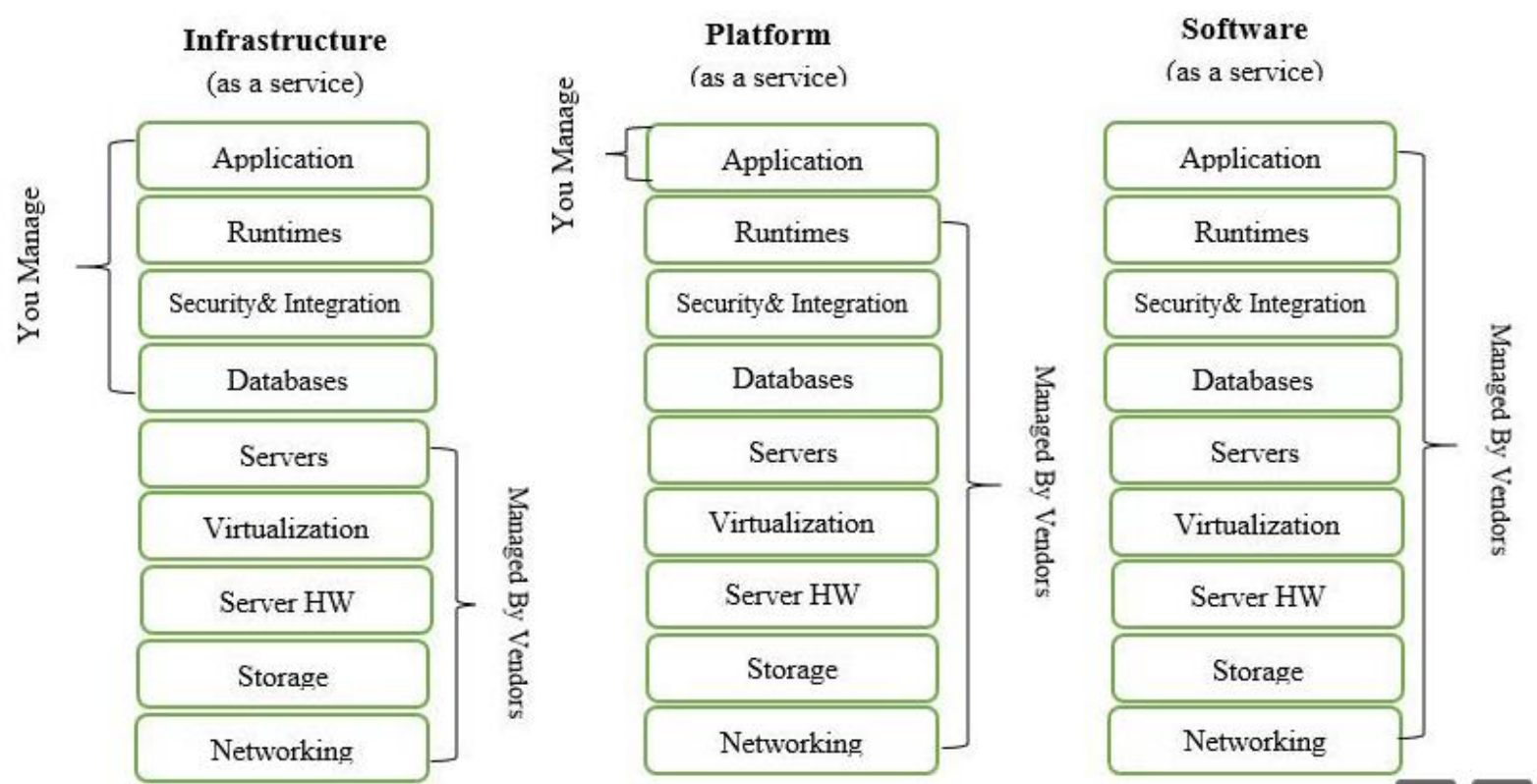

Fig 1:- Illustration of cloud computing services models

\begin{tabular}{|c|c|c|c|c|c|c|c|c|}
\hline 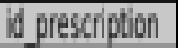 & Id mad & hallep & lfatine & datedlexam & exant & dianobtie & treabinent: & doservation \\
\hline 1 & & wint & Hifitwi & DIPLARASL & 西 & \begin{tabular}{|l|l|} 
linet \\
\end{tabular} & 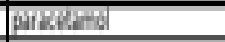 & 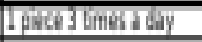 \\
\hline 2 & & 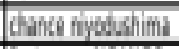 & & 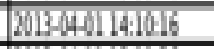 & 낸 & ifflititi & cobrthiff & 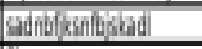 \\
\hline 77 & & Putogind RAND & & MHALIIIL & GE & livint & Dendingurth & SW \\
\hline III & & Liwhlin & 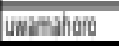 & WHAHWHE & GE: & line & curbiniti & Wha \\
\hline 可 & & Muill & bihminim & MHALUDMA & urititit & linet & 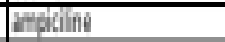 & $3 / 5$ \\
\hline i) & & Fuinh & 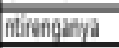 & 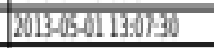 & 武 & livine & indidigint & $3 / 5$ \\
\hline 放 & & Futili & 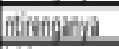 & WIMLDLWHA & 断 & \begin{tabular}{|l|l|} 
finent \\
\end{tabular} & 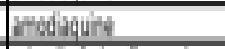 & 326 \\
\hline III & & 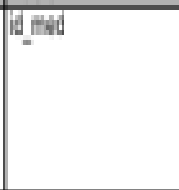 & Whetwith & 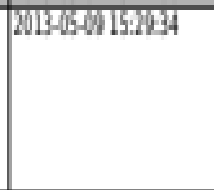 & Amityiliti & 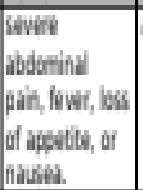 & 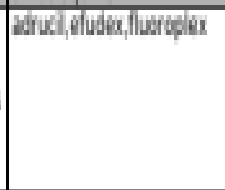 & 5 the of lix \\
\hline
\end{tabular}

Table 1:- Cloud_System,Patient_Prescription data Record 


\begin{tabular}{|c|c|c|c|c|c|c|c|c|c|c|c|c|}
\hline it patient. & linathe & Intante & lablathe & mablinte & gender & birthiday & 缯 & coulfitiy & province & district & sector & 레에 \\
\hline & Pholugint & 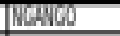 & Whiritymintil & flathin & mithis & Whand & 7hbohis: & Fintilat & 5and & Dyi & mivi & Fungh \\
\hline & Dwothil & Lwifilds & Bifli & |îlifill & Ginith & Hil. 5.218 & $W 61147$ & iwind & wint & Finilia & Sumianime & Bing \\
\hline & Whil & 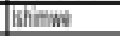 & 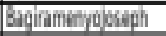 & 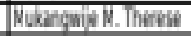 & mintilit & 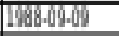 & TRhins & minting & 5oll & Hну & Heys & Hysiph \\
\hline & Ginge & fintusinifi & initis & fijpringinder & ininilit & 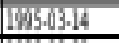 & Midis & Fintilin & wiit & Fintingen & Givisi & Fintingint \\
\hline & whin & 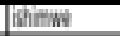 & takiph & thilihin & fiflis & 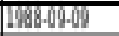 & 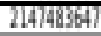 & mintid & Fivit & Finilin & whiliti & 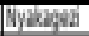 \\
\hline & 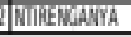 & Lion Havili & Giginimintin & 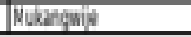 & fifilitis & Whatdal & Whatus & Ewing & 证 & Hijus & Hyin & Hisuly \\
\hline
\end{tabular}

Table 2:- Cloud_System ,Patients data Record

\section{RESEARCH OBJECTIVES}

The main goal of our study is to demonstrate how patient information can be safely protected using clouds. the other is that we encourage all companies and the world as a whole to participate in cloud technology.all of which are in the following three purposes:

Identify security issues and identify appropriate security technologies for use in the Cloud computing world.

$>$ Better understand and identify security issues that may arise in the future of Technology computing.

$>$ To identify and explain some of the ideas that will confront us in the future in accounting in curerent
Technology.

\section{RESULT OF THE STUDY}

In this research we have based on security concerns in technology because there are now hackers in conventional technology where they can get all the information when not stored in cloud technology ALGORITHM INC. we briefly explain future security issues based on expert opinions. Results include:Unsafe Software Applications, Bad Entities, Legal Decisions, Virtual Machine Security, Reliable Trading, Multiple Rental Risks, Mobile Phone Information, Misuse and Misuse of Cloud Clouds, Shared Technology Accidents, the road.

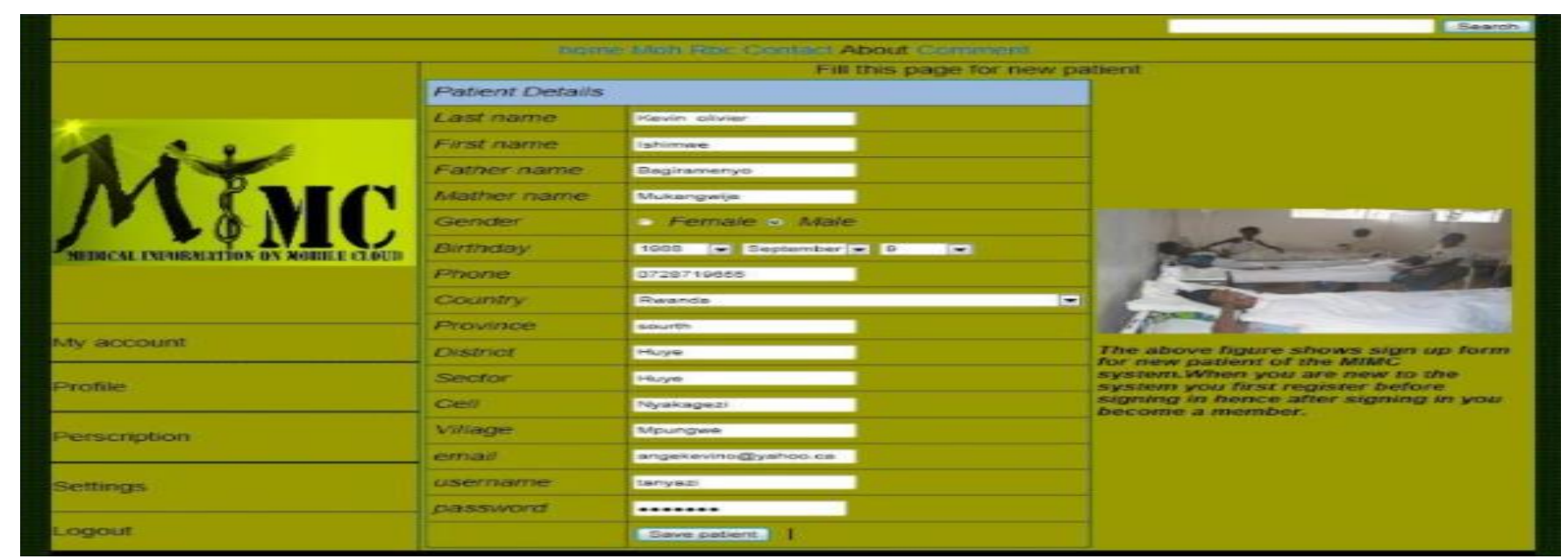

Fig 2:- Patients form details records

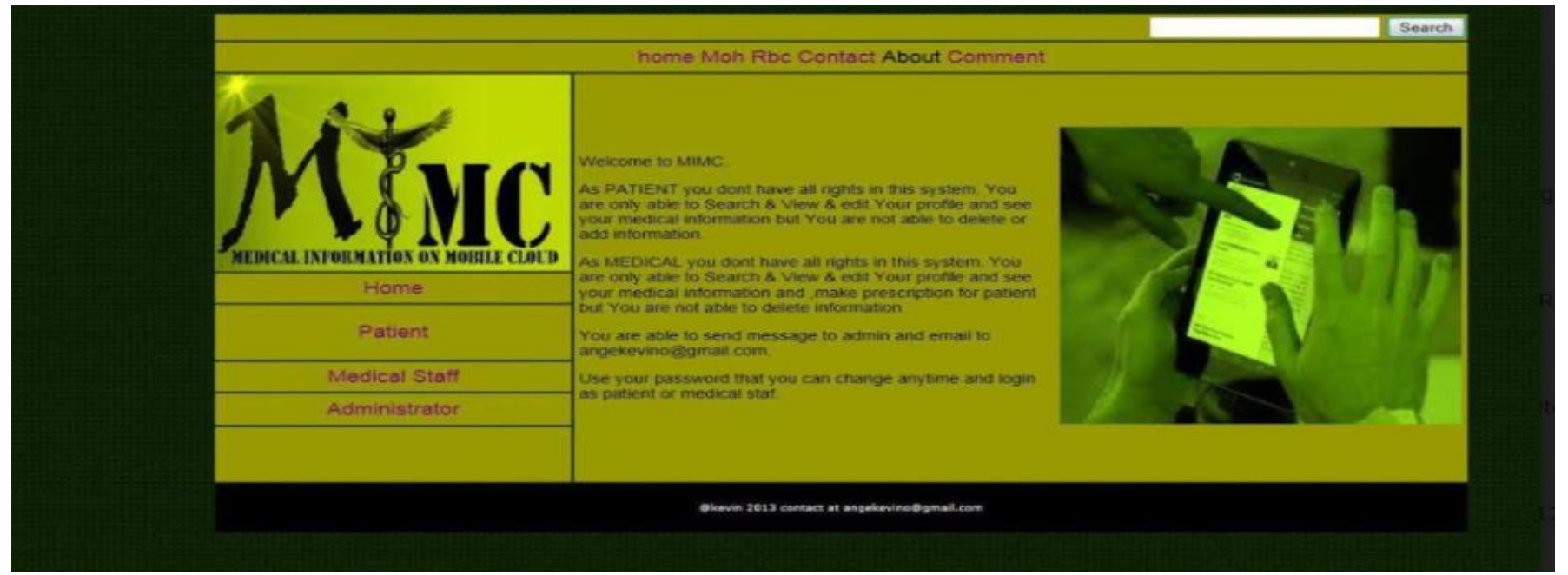

Fig 3:-.Medical information Mobile cloud(MIMC) interfaces data Records 


\section{CONCLUSION}

From what we have said above, we need to protect the patient's information in a reliable way using the cloud and put in place a reliable system where e-health should have the immunity to protect the patient's information properly, as long as it is available. moreover we have to mobilize the whole world to start using reliable cloud storage

e-Health, it is necessary to add to the results provided in any way to address e-Health. governments and decision-makers in all countries of the world must establish a comprehensive e-Health system to encourage and approve it. Governments should also develop research institutes where security experts will come together to exchange views on how to prepare for e-health solutions that are safe enough in any way. Finally, there must be a detailed privacy policy for eHealth services and activities so that patients must believe that as long as they use the cloud ask for their information as securely as possible.

\section{REFFERENCES}

[1]. Ali Gholami and Erwin Laure (2015), security and privacy of sensitive data in cloud computing: a survey of recent developments.

[2]. Monjur Ahmed and Mohammad Ashraf Hossain, January 2014 cloud computing and security issues in the cloud.

[3]. JaydipSen(2015) Security and Privacy Issues in Cloud Computing.

[4]. Asgarali B. and Bahman A. "The Necessity of Using Cloud Computing in Educational System", Procedia Social and Behavioral Sciences 143 (2014) 581 - 585, ScienceDirect, 2014.

[5]. Mbanzabugabo, J, B., Bizimana, T. and Uwitonze G. "Cloud computing: An Avenue for Enhancing Egovernment System" International Journal of Computing Science Trends and Technology (IJCST)Volume 6, Issue 3, May-June 2018. ISSN:2347-8578, 2018.

[6]. Upendra, S. and Prashant K. B. "Role and Service of Cloud Computing for Higher Education System" International Research Journal of Engineering and Technology (IRJET), Volume: 04 Issue: 11 | Nov 2017, 2017.

[7]. Foster et al. "Cloud Computing and Grid Computing 360 Degree Compared". Paper presented at the Grid Computing Environments Workshop, 2008. GCE '08, 2008.

[8]. Rania M., A. "A Survey on the Adoption of Cloud Computing in Education Sector". College of Computing and Informatics, Saudi Electronic University, Jeddah, Saudi Arabia Seidenberg School of Computer Science, 2016

[9]. RURA, Rwanda Utilities Regulatory Agency: "The increased population internet users by March 2014", 2014.
[10]. Fekry F. A "Comparative Analysis for Cloud Based elearning" Procedia Computer Science 65 (2015) 368376. International Conference on Communication, Management and Information Technology, 2015.

[11]. ISACA. (2009). Cloud Computing: Business Benefits With Security, Governance and Assurance Perspectives. Rolling Meadows, USA: ISACA Emerging Technology.

[12]. Kim, W. (2009). Cloud Computing: Today and Tomorrow. Journal of object technology , 8.

[13]. Azeez N, Venter I. Towards ensuring scalability, interoperability and efficient access control in a multidomain grid-based environment. SAIEE Afr Res J 2013:54-68.

[14]. Ayofe AN, Adebayo SB, Ajetola AR, Abdulwahab AF. A framework for computer aided investigation of ATM fraud in Nigeria. Int J Soft Comput 2010;5 (3):78-82.

[15]. Azeez NA, Olayinka AF, Fasina EP, Venter IM. Evaluation of a flexible columnbased access control security model for medical-based information. $\mathrm{J}$ ComputSci Its Appl 2015;22(1):14-25.

[16]. Azeez NA, Iliyas HD. Implementation of a 4-tier cloud-based architecture for collaborative health care delivery. Nigerian J Technol Dev 2016;13(1):17-25.

[17]. Azeez NA, Iyamu T, Venter IM. Grid security loopholes with proposed countermeasures. In: Gelenbe E, Lent R, Sakellari G, editors. 26 $6^{\text {th }}$ International Symposium on Computer and Information Sciences. London: Springer; 2011. p. 411-8.

[18]. Nureni AA, Irwin B. Cyber security: challenges and the way forward. ComputSciTelecommun 2010;29:56-69.

[19]. Uma S. "Research Methods for Business: A skill Building Approach," 4th edition, John Wiley \& Sons, Inc, 2003.

[20]. Simplicio M, Iwaya L, Barros B, Carvalho T, Naslund M. SecourHealth: a delaytolerant security framework for mobile health data collection. IEEE J Biomed Health Inform 2015;19(2):761-72.

[21]. Guo, L, Zhang, C, Sun, J, Fang, Y. PAAS: A PrivacyPreserving Attribute-based Authentication System for eHealth Networks. In: 2012 32nd IEEE International Conference onDistributed ComputingSystems,Macau,China,2012,pp. 224-233.

[22]. Gajanayake R, Iannella R, Sahama T. Privacy oriented access control for electronic health records. e-J Health Inf 2014;8(2):175-86.

[23]. Kumar M, Fathima M, Mahendran M. Personal health data storage protection on cloud using MA-ABE. Int $\mathbf{J}$ Comput Appl 2013;75(8):11-6.

[24]. Newell S, Sanson-Fisher RW, Girgis A, et al. How well do medical oncologists' perceptions reflect their patients' reported physical and psychosocial problems? Data from a survey of five oncologists. Cancer. 20014;83:1640e51. 
[25]. Meuser T, Pietruck C, Radbruch L, Stute P, Lehmann KA, Grond S. Symptoms during cancer pain treatment following WHO-guidelines: a longitudinal follow-up study of symptom prevalence, severity and etiology. Pain. 2009;93:246-57.

[26]. Barsevick AM, Dudley WN, Beck SL. Cancer-related fatigue, depressive symptoms, and functional status: amediation model. Nurs Res. 2006;55:366-72.

[27]. Jacobsen R, Liubarskene Z, Moeldrup C, Christrup L, Sjugren P, Samsanaviciene J. Barriers to cancer pain management: a review of empirical research. Medicina 2009;45(6):427-33.

[28]. Hutchinson H, Mackay W, Westerlund B, Bederson BB, Druin A, Plaisant C, et al. Technology probes: inspiring design for and with families. In Proc of $\mathrm{CHI}$ '03. 2003;17-24.

[29]. Wilde MH, Garvin S. A concept analysis of selfmonitoring. J Adv Nurs. 2007;57(3):339-50.

[30]. Basch E, Iasonos A, Barz A, Culkin A, Kris MG, Artz $\mathrm{D}$, et al. Long-term toxicity monitoring via electronicpatient-reported outcomes in patients receiving chemotherapy. J Clin Oncol. 2007b;25(34):5374-80.

[31]. Berry DL, Blumenstein BA, Halpenny B, Wolpin S, Fann JR, Austin-Seymour M, et al. (2011). Enhancing patient-provider communication with the Electronic Self-report Assessment for Cancer: A randomized trial. J Clin Oncol. 2011;29(8):1029-35.

[32]. Ruland CM, Jeneson A, Andersen, Andersen R, Slaughter L, Schjoedt-Osmo B, et al. AMIA Annu Symp Proc. 2007;635-639.

[33]. Abernethy AP, Zafar SY, Uronis H, Wheeler JL, Coan A, Rowe $\mathrm{K}$, et al. Validation of the Patient Care Monitor 2.0: a review of system assessment instrument for cancer patients. J Pain Symptom Manage. 2010;40(4):545-58.

[34]. Stone AA, Shiffman S, Atienza AA, Nebeling L. The science of real-time data capture. New York: Oxford University Press; 2007.

[35]. Redelmeier DA, Kahneman A. Patients' memories of painful medical treatments: real-time and retrospective evaluations of two minimally invasive procedures. Pain. 1996;66(1):3-8.

[36]. Boykoff N, Moieni M, Subramanian SK. Confronting chemo brain: an in-depth look at survivors' reports of impact on work, social networks, and health care response. J Cancer Surviv. 2009;3(4):223-32.

[37]. Li I, Dey A, Forlizzi J. A stage-based model of personal informatics systems. In Proc of ACM Computer-Human Interaction Conference ' 10 . 2010;557-66.

[38]. Hermansen-Kobulnicky, CJ. Symptom-monitoring behaviors of rural cancer patients and survivors. Support Care Cancer. 2009;17(6):617-26.

[39]. Klasnja P, Hartzler A., Powell C, Phan G, \& Pratt W. HealthWeaver Mobile: Designing a mobile tool for managing personal health information during cancer care. AMIA Annu Symp Proc. 2010;392-6.
[40]. Strauss A, Corbin J. Basics of Qualitative Research. (2nd Ed). London: Sage Publications; 1998. 